\title{
The Role of Serious Gaming using Virtual Reality Applications for 3D Architectural Visualization
}

\author{
Farzam Kharvari \\ Department of Architecture \\ FH JOANNEUM - University of Applied Sciences \\ Master Course Architecture \\ Graz, Austria \\ Farzam.kharvari@edu.fh-joanneum.at
}

\author{
Wolfgang Höhl \\ Department of Architecture \\ FH JOANNEUM - University of Applied Sciences \\ Master Course Architecture \\ Graz, Austria \\ Wolfgang.hoehl@fh-joanneum.at
}

\begin{abstract}
This paper investigates the advantage of VR technology in architectural education. Different studies showed that VR increases the engagement and motivation of students by creating an interactive environment and provides deeper learning. On the other hand, Precedents in architecture are the first and the most important step toward architectural education. One needs to study these precedents and store them in the experiential/episodic memory. Visiting precedents is more beneficial than conventional ways of studying them such as hand sketching but it is costly and not available to all students. Therefore, we believe that the VR technology can take the place of visiting precedents since it resembles the precedents exactly and offers a better, cheaper and easier way for accumulating highly specific architectural knowledge than a local visit due to providing architectural interactivity. We tested our hypothesis by using Therme Vals and an HTC Vive headset among architecture students. This paper shows that VR is an advantage in architectural education because it offers cheap and easy solutions for studying precedents. Also, it motivates the students and leads to deeper learning because of the interactivity that it offers. The students were able to recognize a complex plan clearly and remember the spatial configuration.

Index Terms-Game-based learning, Virtual reality, Computer games, Serious Games, Architectural Visualization
\end{abstract}

\section{INTRODUCTION}

Interactive learning is defined as a learning approach that encourages independent study through the use of computer technology and electronic media [1]. Interactive Learning leads to deeper learning of a subject compared to the conventional ways of studying [2], [3]. Researches showed that interactive gaming environment can improve learning and motivation [4]. However, there is lack of interactivity in conventional study of precedents in architecture. On the other hand, visiting precedents is very costly and not available to all students around the world. Therefore, seeking a new technology to make precedents available to all is vital. The VR technology has the potential to simulate precedents and it offers interactivity and convertibility as two important advantages. Therefore, this paper tests the hypothesis that the VR technology can take the place of visiting precedents since it resembles the precedents exactly and offers a better, cheaper and easier way for accumulating highly specific architectural knowledge than a local visit due to providing architectural interactivity. In this article, we used the empirical research method. Our experiment and preliminary survey for testing our hypothesis are all mentioned in the IV section [5]. Therme Vals, designed by Peter Zumthor, is our prototype because of its complexity in plan and spatial configuration. We simulated it for the VR technology using Unreal Engine version 4.21 and HTC Vive. Our empirical evidence shows that students can recall different parts of the building efficiently. The paper investigates the notion that VR technology can help interactive studying of precedents in architecture and evaluates its effectiveness in comparison to the conventional ways.

\section{BACKGROUND}

One must first focus on the accumulation of knowledge and experience as the first step in design learning for generating new ideas [6]. Accumulating knowledge in our 'reservoir' is the primary step toward becoming an architect [7], [8]. Students should fill up the reservoir with precedents for generating new ideas and solutions for architectural problems. Among all the ways of studying precedents, experiencing them is the most effective one that will remain longer in our memory [7]. An expert architect can easily provide solutions to problems while novices mostly rely on them for providing solutions. Experts use known precedents as the link between problems and solutions [7]-[9]. Students will store more precedents in their pool of precedents as they progress. This will enable them to recognize schemata in facing design problems. Therefore, precedents are one of the key elements in architectural education [7], [8]. Design knowledge relies on experiential memory [episodic] instead of theoretic memory. [7], [10]. Visiting precedents is the most effective way of remembering them since architects have access to gambits through their experiential memory [7].

\section{Development of Prototype}

VR can play a key role in studying precedents in architecture. Unreal Engine version 4.21 and its plugin Datasmith make the visualization of precedents efficient by simulating projects in the VR mode and creating interactions through blueprints [11]. We used Autodesk 3ds Max as our modeling software and then imported it into Unreal Engine v. 4.21 through Datasmith. We designed a collector game for our study 
group to make sure that they will go through all the plan so that we can have a better evaluation of their performance in the next follow up. Hence, we designed 12 golden cubes and the player had to hit [collect] them by blue cubes. The score was shown on the screen and the player had to collect all these cubes to finish the game successfully.

\section{IMPLEMENTATION AND TESTING OF OUR PROTOTYPE}

The option to switch on and off some lights as well as the possibility to change materials of the walls [4 different alternatives] were designed to enhance interactivity and improve computer-mediated learning as a result. [2].

The player had a flashlight, general information about the building, and the directions of the gameplay as an explodable text at the beginning of the game. The flashlight was for searching some of the cubes in 3 dark massage rooms. Also, the day-night cycle was designed to show a special orchestra of light and shadow designed by Zumthor through roof details.

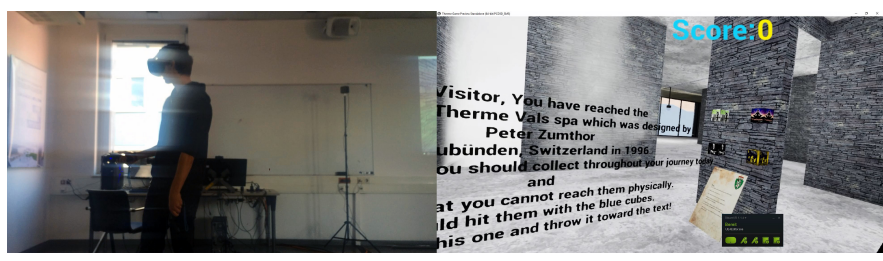

Fig. 1. A screenshot of the environment and player. [https://www.youtube.com/watch?v=fwmjtJ3FrAk]

We conducted a preliminary survey in the form of an accompanying user study to develop our prototype. In this study, we evaluated the ability of our players to remember the environment. Our study group was made of two architecture students who played the game. We prepared a classroom for our players. The game was shown to the audience and researchers on the front wall using a video projector. The most important part was to measure the students' ability to remember the spatial configuration of the precedent. Hence, each player played the game twice with a 24-hour interval. After the second play, we asked the players to draw the paths that they went through to compare if they understood the circulation [spatial configuration] properly. We evaluated the ability to remember the precedent by measuring the students ability to recall the paths that they had to go for finding the golden cubes in the second play as well as comparing the drawn paths to the real paths. The students had not visited the place before but the researchers had already visited the place.

\section{Findings AND RESUlts}

Our study group wanted to be able to choose the materials and spend time looking at the environment with different materials. This shows the importance of interactivity in virtual environments. We observed that players were able to recall the paths to the cubes in both cases with a high percentage. In the first play, they were free to spend as much time as they want in the environment. They were free to change the materials, check the corners, look at the views, and etc. but in the second play, they had to collect as many cubes as they can without any wandering around. The first player was able to collect 8 cubes out of 12 golden cubes while the second player was able to collect 11 golden cubes which is a very high success rate. We believe that the high success rate of the second player was because of the time he spent in the first play. He was more eager than the first player in the first play to explore the virtual environment and see how things interact. An average success rate of 79.16 percent shows that students were able to recall the spatial configuration and store them in the experiential/episodic memory for further use. By generalizing the results, we can say that the players were able to recall the spatial configuration of the building and find the paths to the cubes. Drawn paths were quite similar [4 out of 5] to the original paths. Changing materials and modifying the lights in the building increased interactivity which resulted in deeper learning. Therefore, we can confirm our hypothesis that the VR technology can take the place of visiting precedents since it resembles the precedents exactly and offers a better, cheaper and easier way for accumulating highly specific architectural knowledge than a local visit due to providing architectural interactivity.

\section{CONCLUSiOn AND Future Work}

This paper investigated the advantage of VR over conventional ways of studying precedents in architecture. By simulating Therme Vals as a serious game, we observed that the study group was able to recall the spatial configuration efficiently. By generalizing the results, we can confirm that VR technology can take the place of visiting precedents since it resembles the precedents exactly and offers a better, cheaper and easier way for accumulating highly specific architectural knowledge than a local visit due to providing architectural interactivity. better and more large-scale experiment A better and more large-scale experiment for measuring the exact effect of serious gaming on architectural education is vital.

\section{REFERENCES}

[1] Oxford living Dictionaries, Interactive learning.

[2] K. S. Bull, S. L. Kimball, and S. Stansberry, Developing Interaction in Computer Mediated Learning., 1998.

[3] N. M. Webb, Peer interaction and learning in small groups, Int. J. Educ. Res., vol. 13, no. 1, pp. 2139, 1989.

[4] S. Erhel and E. Jamet, Digital game-based learning: Impact of instructions and feedback on motivation and learning effectiveness, Comput. Educ., vol. 67, pp. 156167, 2013.

[5] D. Yanow and P. Schwartz-Shea, Interpretation and method: Empirical research methods and the interpretive turn. Routledge, 2015.

[6] M. Laxton, Design education in practice, Attitudes Des. Educ., 1969.

[7] B. Lawson, Schemata, gambits and precedent: some factors in design expertise, Des. Stud., vol. 25, no. 5, pp. 443457, 2004.

[8] B. Lawson, How designers think. Routledge, 2006.

[9] A. D. De Groot, Thought and choice in chess, vol. 4. Walter de Gruyter $\mathrm{GmbH}$ and Co KG, 2014.

[10] N. Cross, Designerly ways of knowing, Des. Stud., vol. 3, no. 4, pp. 221227, 1982.

[11] A. Sanders, An Introduction to Unreal Engine 4. AK Peters/CRC Press, 2016. 